\title{
Youth, Their Language and Ideologies
}

\author{
Lynn Mallari Besa
}

\begin{abstract}
Writing is a system of more or less permanent mark used to represent an utterance which expresses the inner thoughts, beliefs, ideas and even identities of the writers. While writing is a powerful tool of expression, text is a vehicle for information.

What do learners think about themselves? About their fellow? About their society? How do they respond to the happenings around them? What do they want to happen if they are given the authority to act or to decide on things?

Text and discourse analysis play a vital role in uncovering the interaction between language, text structure and functions.

This study is primarily centered on the analysis of the composition of the secondary level students to understand their language and the purpose of their text to investigate more deeply their mental models which eventually leads to disclosing their ideologies. The study specifically probes the general structures and features of the learners' composition which carry underlying messages.

In the qualitative analysis of data, critical discourse analysis of the learners' composition is utilized to explore the nature of the $21^{\text {st }}$ century learners and writers, the role of their writing as a form not only of expression but of empowerment and eventually look at its impact as the unsound outlet of the youth. Hence, the study tries to unveil the connections between writing, language and thinking.
\end{abstract}

Index Terms-Compositions, critical discourse analysis, ideology, language.

\section{INTRODUCTION}

Writing is an art. Writing is a form of expression. Writing as Francis Bacon once said, "makes a complete man". Writing is a continuing process of discovering the most effective language for communicating one's thought and feelings.

Yet, writing, like the other skills, is one of the most difficult, crucial and demanding activities which requires serious attention. Writing ability as cited by Hamp-Lyons and Kroll in 1997 is not a simple task. Sometimes, the physical act of writing is thought as mainly the result of cognitive effort on the part of an individual writer. However, it is important to view writing not solely as the product of an individual, but as social and cultural act which takes place within a context, that accomplishes a particular purpose, and that is appropriately shaped for its intended audience [1].

Writing is an integral part of schooling. In the academe, most often than not, students are asked if not required to submit different written outputs. May it be creative such as essay, critiques or academic or even technical papers [2].

However, writing is not just a mere requirement among learners. As Fulwiler (1987a) mentioned, writing is the basic

Manuscript received April 20, 2016; revised September 12, 2016.

Lynn M. Besa is with Rizal Technological University, Philippines (e-mail: besalynn@yahoo.com). stuff of education [3]. It is a system of more or less permanent marks used to represent an utterance in such a way that it can be recovered more or less exactly without the intervention of the utterer [4]. Writing is of different purposes and in different ways. It expresses the inner thoughts of the writer, thus, reflects their ideologies.

What do students think about themselves? About their fellow? About their surroundings? About society?

How do they respond to the happenings around them?

What do they want to happen if they are given the authority or right to act or decide on matters?

At young age, what do they write? And how do they express themselves in writing?

Ideology is a set of beliefs that affects ones' outlook on the world. Ideology consists of most closely held set of values and feelings, and it acts as the filter through which one sees everything and everybody. In fact, beliefs are often so close that one could not realize that they are there [5].

While Woolard in 1990 attempted to define language ideology as "shared bodies of common sense notions about the nature of language in the world which mean to include cultural conceptions not only of language and language variation, but of the nature and purpose of communication, and of communicative behavior as an enactment of a collective order. [6]. As conceived from the perspective of rhetoric, ideology provides the language to define the subject (the self), other subjects, the material world, and the relation of all of these to each other. Ideology is thus, inscribed in language practices, entering all features of man's experience including political force as well as social forces and in the nature of things as distributed in a society [7].

In what way does writing become as an avenue of ideological expression?

Since writing serves as an instrument of understanding learners and their thinking, this study aimed to uncover how writing serve as a medium of expressing the inner self of the writers which reflect their ideologies. Thus, the study aimed to uncover how writing serve as a medium of expressing the inner self of the writers. Moreover, the study aimed to analyze the intent of the authors, purpose of the text and the writers' mental models which could lead to the disclosure of their ideologies.

Specifically, the study aimed to answers questions such as: What is the general structure of the writers' composition? What are the features of the learners' composition? and, What ideologies are implied in the writers' composition?

The result of the study meant to be beneficial primarily to the writing teachers to see writing as an expression of ideologies more than a requirement. Hence, this study may provide them inputs on the kinds of topics and activities 
which they could give among their students. The study would also impact the students since this would uplift their interest in writing not just an academic output but as a means of expression and liberation. Through the study, learners may discover themselves not only as students but also as $21^{\text {st }}$ century empowered writers. While on the part of the Administration and curriculum developers, this study would provide them source data in revisiting the curriculum landscape of writing courses. Furthermore, the result of the study would provide the book writers information on the nature of $21^{\text {st }}$ century writers which could help them in the realignment of their frameworks. And, in general this study aimed to contribute additional information in the pedagogy of writing especially in the field of critical discourse.

\section{DELIMITATION}

This study did not include the process in writing which involves the drafting, revising and editing. Moreover, the analysis of the errors in the grammatical structure of the language was excluded.

The study was primarily focused on the description and analysis of the discourse in the written output of the students and the ideologies embedded. Hence, the study did not intend to change the mental models of the students towards writing and the society they live in.

\section{PROCEDURE}

In the analysis of data, a qualitative approach in which content or text analysis was utilized. Qualitative content analysis defines itself as an approach of empirical, methodological controlled analysis of texts within the context of communication. It is a method of summarizing any form of content by counting various aspects of the content which links between causes (e.g. program content) and effect [8].

While the data gathering involved the actual writing of the Grade 7 junior high school students during their English class. After the writing activity, the compositions were collected. They were analyzed through the lens of critical discourse (or CDA) which aims at making transparent connections between discourse practices, social practices, and social structures, connections that might be opaque to the layperson [9].

The researcher further analyzed the discourse of the students' compositions, ideas, beliefs, ideologies, identities, politics, and the like [10] to provide answers to questions about the relationships between language, society, power, identity, ideology, politics, and culture [11].

After the data were analyzed, they were interpreted and presented.

\section{RESULTS}

\section{A. General Structure of the Learners' Composition}

Every writing has its own structure which defines its overall construction and serves as the framework of any raw materials. Structure ensures that the main points of the composition are very clear and well supported. Thus, it provides a scaffold that shapes the flow of the composition. While structure is a fundamental, tangible or intangible notion referring to the recognition, observation, nature and permanence of patterns and relationships, the technique is a way of carrying out a particular task.

It could be seen that the dominant form of the students' composition follows the linear form -the introduction - body - end (conclusion) pattern [12]. The introduction gives the writer's overall point and purpose in the essay. The body gives support to the overall point using different modes of development while the end or conclusion provides closure or restates the overall point.

A conventional structure for introductions is general to specific. These introductions begin with some general statements on a topic before moving onto the particular issue or problem that the essay will deal with. They end with the overall point and/or purpose of the essay - which is called the thesis statement.

Introductions are evident in the students writing. However, there is no definite pattern in the writing of introduction. Some are either in quotation, question such as What is typhoon?,... They said that gays cannot bear a child because in nature they are physically man and in their heart they are woman, but why they are so many of them?,... what is global warming?, descriptions as travelling is an exciting experience, a pleasure going to different places, exploring the different culture of other people, gender equality gives everybody equal rights or definitions like There are many definitions of love, drugs is a substance use as a medicine,... flood is a large amount of water covering an area of land that is usually dry.

While in one composition, a part of a song was used:

I did my best, but my best wasn't good enough" as introduction teaser.

It could be gleaned that the introductions aimed to capture the readers' attention, lead the readers into the topic and give the readers overall point or purpose of the composition.

In terms of the body, the compositions were commonly developed through comparison, description, definition and cause.

While the last paragraphs of the compositions ended with concluding statements which were not necessarily syntheses but were generally advisory/counseling and challenging in nature:

I would like to reflect on this quotation: 'the greatest value of having good friends ... We can overcome whatever obstacles that we are encountering...No one can want you to succeed more than you do...You have to want to succeed because no one else can make you successful. You are the one determining how much you'll achieve.

The purpose of the conclusion is to briefly remind the reader of the overall point, possibly suggest wider implications, and give the essay a satisfying sense of closure.

The introduction-body- conclusion or linear pattern reveals that the students' writings are [already] structured. Their writing has shape or form. Despite, the free writing condition, their writing reveals that they [already] have directions and could introduce, expound and close topics.

\section{B. Features of the Learners' Compositions}


In the analysis of data, it was noticed that the students used few transitional devices. Such include first, before I start, second and lastly. Yet, despite the minimal use of transitions, paragraphs were found to be cohesive. The students writing depicted consistent and clear-cut ideas without worrying of the sudden shifts.

It could also be seen that the paragraphs were written in simple sentences:

Learning is like a food.

Global warming is caused by pollution.

Traditionally, the idea of a good paragraph indicates that the longer it takes, the better it becomes. On the contrary, it was apparent that the students writing exposes simple and short sentences. An essay contains many different kinds of information. No matter how short, it contains many different operations such as introducing an argument, analyzing data, raising counterarguments, and concluding without worrying about adjectives or hedges.

It could be viewed that most of the students' essays are walk-through essays in which they are generally descriptive in nature rather than argumentative. Their essays are usually introduced with "time" deictics such as first, second, third etc. or "listing" words like also and and which often suggests reproduction of chronology of source text or simply lists examples.

In terms of the topic, the students' compositions are divided into three categorical subjects. The subjects are personal, general and socially relevant.

Personal topics include personal issues such as love, sexual preference, latest television trend. General topics include love, technology, travel, friendship, favorite sports and education. While topics which deals with social issues include poverty, social media, gender equality, election and voting systems, natural calamities or disasters such as flood and typhoon, current social problems such as drugs, traffic jam, global warming, illegal logging, and issues of being a Filipino among others.

What is surprising among the compositions of the learners is that they would talk about love but not the personal love or superficial kind of love. They talk about technology but not the latest gadgets they would want to have. Rather, they present the causes and effects of the subjects. They would talk about nature but not [just] the usual description of nature but the effect of rules and order. They talk about travel but not [just] for enjoyment but because "travel makes them reflect on the life they have". Thus, the use of cause and effect mode of paragraph development uncovers the universal truth of the consequences of actions which they have realized at a young age.

A writer's style sets his/her writing apart from others. Writing reveals the type of personality of the writer. The choice of words, sentence fluency, and the writers voice all contribute to the style of the piece of writing. How a writer chooses words and structures sentences to achieve a certain effect is also an element of style [13].

It could be gleaned that different styles in writing were employed in the students' composition. Although majority were written in declarative statements, there were statements which were presented in question form, imperatives, quotations and even through allusion. It could be viewed that these statements present illocutionary direct and firm meanings. such as the concluding paragraphs which are written in question form as revealed in the lines: So, are you with $m e$ ? but divulges challenge more than inquiry.

Writing systems are both functional, providing a visual way to represent language, and also symbolic, in that they represent cultures and peoples [14].

It could be viewed that the writing of the learners is generally expository in nature. They inform, explain and clarify their ideas and thoughts. Thus, they specifically used cause and effect, presenting the reason and result of actions as evident in the line:

Global warming is the result...global warming is cause by the pollution

Thus, the inductive and informative nature of the compositions indicate straightforwardness which demonstrates clear identification of the possible causes and effects of their action.

'Modality' includes various types of such personal perceptions and attitudes [15].

The compositions exemplified the use of modality such as can which presents the ability while the modal should is directed towards the use of "you" point of view The presence of the modals indicates the students control over, and evaluation of, situations and events which entails an unconscious superiority over the others. Their statements would always include the pronoun "we" which suggests inclusion or involvement. Their use of simple sentences implies straightforwardness, clarity of thoughts and innocence.

We may push ourselves harder...

...we can do to prevent stress...

You can manage stress...

We hope you learn from us...

Let us strengthen ourselves and work hard in realizing our dream...

We should also discipline ourselves because we too are responsible why our nature is being destroyed.

Observe that the statements were generally written in the active voice. A very powerful tool to unconsciously project the role of the doer or actor in the sentence.

Furthermore, in the following lines:

If you failed, it only means that you're still not doing your best and it doesn't mean that you haven't done guts to do that.

...we must know that we need to prioritize our day...plan your time...

...If we fail once, we shall try again and again.

It could be gleaned that the tone of the compositions was dominantly advisory and challenging in nature. While in the succeeding lines, it can be observed that the mood was perceived to be serious, calm yet firm:

Life is complicated? no, to be honest, life is more than complicated...we will talk about the major circumstances that we are facing about stress...

We must learn discipline. Strict discipline at schools is very good for us. the key to success is to be better individual...if you want to be a businessman, or an engineer, or nurse, or a teacher, you need better education. You can't just drop out of school...value your time, don't waste your opportunities...learn to accept it all and continue your 
dreams, for every achievement big or small, start with a dream project

Notice that the disposition is commanding in nature and projects unconscious superiority and power.

Moreover, as revealed in the use of the present forms of the verbs like lead, motivates, works, help, encourage, prepare etc. the students talked about the present, lives in the present and would like to resolve the issues of the present. The speech acts of the students' statements discloses their sensitiveness of the events around them.

\section{Discussion}

Generation Y are known by many names: the millennials; the iPod generation; the me firsts; the internet generation; the echo boomers; the Nintendo generation; the digital generation; generation why; generation next; the I generation and the net generation [16]. The most salient characteristic of this generation is its comfort with technology. Prensky (2005/2006) [17] refers to them as digital natives, or people born into a technological world. In other words, today's youth have never known life without computers and the Internet, and therefore see information technology as an integral part of their lives. Today's students, unlike their counterparts forty years ago, are from diverse cultural, economic, and geographic backgrounds [18]. Though cynical, they are aware of global warming and other world issues but still hopeful.

Prensky even observed that although Gen $\mathrm{Y}$ is often seen as lacking commitment and fearing intimacy, the rise of social networks via technology is redefining the very concept of friendship which include cross-country and international relationships and conversations that flourish online. On the positive side, digital natives serve as ambassadors who are bringing cultures, countries, and religions closer with online communication (Nasseh, 2002) as cited by Black in 2012 [19].

The hypertext minds of the $21^{\text {st }}$ century learners crave interactivity, are good at reading visual images, have strong visual-spatial skills, tend toward parallel processing and inductive discovery, look for fast response times which leads to short attention spans [20]. Hence, the students' styles in writing exposed expository, brevity and straightforwardness.

In the deeper analysis of the discourse, one would be surprise to note that learners pay deeper attention to different happenings around them. Millennials aren't narcissistic. They are into self-expression-and their statements implicitly express that they are sensitive to the events around them. In contrast to the negative notion about them, the millennials are regarded as racially and ethnically diverse generation that is why they love to travel. Millennials are inspired by people they can relate to [21].

Fulwiler (1987a) asserts that "writing is basic to thinking about, and learning, knowledge in all fields as well as to communicating that knowledge." [22].

Elbow (1986) concurs, observing that writing leads to more detailed and complete thinking as the writer explores connections and different organizational patterns in the material to be learned [23].

Patterns of development helps sort information and shape paragraphs or essays. They can help organize an outline, or depending on the purpose they can determine the form that a paper will take. Most papers use a combination of methods, working together in function of each other [24]. In the analysis of data, the linear organization of the writers' ideas present a continuous flow of thought. Moreover, the use of simple sentences presents the innocence of the writers which reveals their nature as less complicated as compared with the adults. Hence, order and organization which reveal simplicity, direct but clear thinking are reflected in their writing. While, the cause-and-effect writing shows a chain of connected events, each discloses logical result of the one before it [25].

Transitions were very minimal in the students' writing. However, it is evident that coherence is achieved because the sentences in the paragraphs are arranged in an order that made the ideas clear and sensible to the reader; the relationship among the sentences and paragraphs is logical; and the ideas flow smoothly from one sentence and paragraph to the next [26].

Tone is the author's attitude toward the writing and the readers. While mood is the feeling a piece of literature arouses in the reader: happy, sad, peaceful, etc. Mood is the overall feeling of the piece, or passage. It could be called the author's. emotional-intellectual attitude toward the subject. It is the general atmosphere created by the author's words. It is the feeling the reader gets from reading those words. It may be the same, or it may change from situation to situation. The students' writings were perceived to be serious, calm yet firm.

The data discloses that contrary to the common notion of the youth as insensitive and selfie-centered individuals, at young age, they are identified to have deeper understanding of the realities around them. Hence, they are not just mere participants or passive expectators but are active and concern individuals who are keen observers and involved. Their writing exposes a special power to affect change. Thus, the students' writing show how discourse expresses and reproduces underlying social representations of the writers in the social context.

A composition which is usually called an essay deals with a subject and usually expresses the authors outlook and personality. It is a form of writing where students put themselves on the topic and express their ideas and feelings. Thus, it mirrors their subconscious and deeper notions about certain topics. While, the way thoughts are organized vary among the writers and in different cultures.

Writing is not simply a means of explaining what one knows; it is an invaluable way to generate thinking, discovery, and learning [27]. It was uncovered that their writing reflected an unconscious form of power. Their writing served as an unconscious expression of beliefs and identity. While the frequent use of can, shall and must as modals present authority towards the use of "you" point of view which entails an unconscious superiority. Their statements would always include "we" which suggests inclusion or involvement. Their use of simple sentences implies brevity, straightforwardness, clarity of thoughts and innocence while being firm yet calm at the same time. 


\section{CONCLUSION}

Writing is not simply a means of explaining what one knows; it is an invaluable way to generate thinking, discovery, and learning [27]. Hence, writing serves as a catharsis for change.

$21^{\text {st }}$ century learners have many educational traits that older educators may not be familiar or comfortable with. Today's learners are digitally literate, experiential and social [20]. The participants were found to have deeper understanding of the things around them despite the nature and generality of the subjects of their writing. The learners of today were found to be direct to the point writers with clear and strong convictions. The brevity of their word indicates not the lack of skills in writing but the strong willed personality which do not need to go around the bush to clarify themselves. Therefore, the number of words becomes irrelevant for it does not guarantee the quality of output especially in terms of depth.

Moreover, the inductive informative nature of the learners writing revealed an introduction-body-end format. The use of simple sentences projects direct but cohesive ideas.

The study divulges that contrary to the common notion of the youth as insensitive, at young age, they are identified to have deeper understanding of the realities around them. Hence, they are not just mere participants or passive expectators but are active and concern individuals who are keen observers and involved. Their writing exposes a special power to affect change.

Therefore, it is recommended that the teachers who are the prime instruments in conducting writing activities to carefully identify the kind of writing tasks, design assignments that allow students to think critically in writing about personal experiences and social events, for "as students write about and become familiar with what they hear. They move, almost despite themselves, to a more exacting appreciation of the sociological imagination" [28]. Writing assignments should be designed to encourage critical thinking and creativity as well as to help students polish their writing skills.

Because students tend to produce better writing when they are motivated and excited about a topic [29], teachers are encouraged to assign different types of writing: some informal, some formal so students will learn to construct their thinking and writing in a variety of ways. Thus, allow students to explore subjects in novel ways which will generally be rewarded with higher-quality work.

Furthermore, it is recommended that the different aspects of writing activities be taken into account in the curricular revisit or revision. Also, the study endorses that other related studies be conducted to expound other areas both in writing and ideology.

\section{REFERENCES}

[1] S. S. Weigle, Assessing Writing, United Kingdom: Cambridge University Press, 2002.

[2] A. Allam, Effective Written Communication, San Jose Del Monte City, Philippines: Rizmarc Publishing, 2012.

[3] Brent and R. R. M. Felder. Writing Assignments-Pathways to Connections, Clarity, Creativity. [Online]. Available: http://www4.ncsu.edu/unity/lockers/users/f/felder/public/Papers/Writi ng_Paper.pdf

[4] P. T. Daniels and W. Bright, The World's Writing Systems, P.3 Oxford: Oxford University Press, 1996.
[5] Political ideologies and style. [Online]. Available: http://www.sparknotes.com/us-government-and-politics/political-scie nce/political-ideologies-and-styles/section1.rhtml

[6] K. Woolard. Language Ideology: Issues and Approaches. [Online]. p $237 . \quad$ Available http://citeseerx.ist.psu.edu/viewdoc/download?doi=10.1.1.476.2519\& rep=rep $1 \&$ type $=$ pdf

[7] J. Berlin. (Sep. 1988). Rhetoric and ideology in the writing class College English. [Online]. 50(5). pp. 477-494. Available: http://links.jstor.org/sici?sici=0010-0994\%28198809\%2950\%3A5\% 3C477\%3ARAIITW\%3E2.0.CO\%3B2-2

[8] Content Analysis. [Online]. Available http://www.audiencedialogue.net/kya16a.html

[9] J. Sheyholislami. Critical Discourse Analysis. [Online]. Available: http://elearn.uni-sofia.bg/pluginfile.php/165446/mod_resource/conten t/1/1\%20What\%20is\%20CDA.pdf

[10] P. Chilton and C. Schäffner, "Politics as text and talk," Amsterdam/Philadelphia: John Benjamins Publishing Company, 2002.

[11] Rahimi and Riasati, "Critical discourse analysis: Scrutinizing ideologically-driven discourses," International Journal of Humanities and Social Science, vol. 1, no. 16, p. 107, November 2011.

[12] Basic Essay Structure. [Online]. Available: https://www.jyu.fi/hum/laitokset/kielet/oppiaineet_kls/englanti/studie s/theiis-and-academic-writing/text-types/basic-essay-structure

[13] K. Cali. Style. [Online]. Available http://www.learnnc.org/lp/editions/few/684

[14] F. Coulmas, The Writing Systems of the World, Oxford: Blackwell, 1991.

[15] J. Marks. Mood and Modality. [Online]. Available: http://www.onestopenglish.com/methodology/teaching-tips/ask-the-e xperts/grammar-questions/grammar-mood-and-modality-2/153932.art icle

[16] C. P. Schofield and S. Honoré. (2010). Generation Y and learning. The Ashridge Journal. [Online]. Available: http://www.ashridge.org.uk

[17] M. Prensky, "Listen to the natives," Educational Leadership, vol. 63, no. 4, pp. 8-13, 2005/2006.

[18] P. Reilly, "Understanding and teaching gen Y," English Teaching Forum, 2012, no. 1, pp. 1-11.

[19] A. Black, "Gen Y: Who they are and how they learn understanding and teaching generation Y," English Teaching Forum, no. 1, 2012.

[20] M. Rodgers et al., "Teaching the $21^{\text {st }}$ century learner," in Proc. $22^{\text {nd }}$ Annual Conference on Distance Teaching and Learning, 2006.

[21] "5 things to know when writing for generation Y," Blog on March 12, 2014, Business English Writing, [online] Available: http://www.businessenglishhq.com/writing-for-generation-y/

[22] T. Fulwiler, Teaching with Writing, Portsmouth, Boynton/Cook: N.H $1987 \mathrm{a}$.

[23] P. Elbow. (1986). Embracing Contraries, New York: Oxford University Press.

[24] Patterns of development. [Online]. Available: http://www2.southeastern.edu/Academics/Faculty/elejeune/methods.h tm

[25] R. Jewell. (2013). Rhetorical modes. [Online]. Available: http://www.tc.umn.edu/ jewel001/CollegeWriting/START/Modes.ht m\#Cause

[26] R. Jewell. Transitional words and phrases. [Online]. Available: http://www.csun.edu/ hcpas003/transwords.html

[27] B. C. Karcher, "Sociology and writing across the curriculum: An adaptation of the so-ciological journal," Teaching Sociology, 1988.

[28] M. L. Cadwallader, and C. A. Scarboro, "Teaching writing within a sociology course: A case study in writing across the curriculum," Teaching Sociology, 1982

[29] W. Zinsser, Writing to Learn, Harper and Row: New York, 1988.

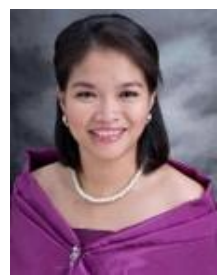

Lynn M. Besa was born in Tarlac, Philippines. She is a candidate for $\mathrm{PhD}$ in applied linguistics at Philippine Normal University. She was the former head of the English Department in the College of Education in Rizal Technological University, Philippines.

At present, she teaches English, research and education subjects in the tertiary and graduate school levels.

She is also an active researcher and presenter in international conferences and had published books and journal in linguistics and literature. 